\title{
REVELAÇÃO POÉTICA EM JORGE DE LIMA
}

\section{POETIC REVELATION IN JORGE DE LIMA}

\author{
Ataide José Mescolin VELOSO 55
}

\begin{abstract}
RESUMO: Este trabalho tem como objetivo fazer um estudo da obra de Jorge de Lima, no que tange à questão da revelação poética. A poética limiana, principalmente após a publicação de Tempo $e$ eternidade, passou a tematizar o processo de criação literária. Surge, então, a figura do demiurgo: o poeta que recebe o dom direto das mãos de Deus, tornando-se um anunciador das grandes verdades universais. A figura do poeta, associada à de um herói com seus poderes sobrenaturais, é capaz de superar as categorias de tempo e espaço. Para Jorge de Lima, o ato de composição poética está ligado ao retorno aos primórdios da linguagem - momento de surgimento das fórmulas mágico-encantatórias. Ele vê na poesia uma forma de manter a autonomia da linguagem e de criar o seu mundo particular. O poeta não está conformado com os recursos que uma linguagem estática pode oferecer-lhe. Muito pelo contrário, ele realiza uma viagem em busca da Musa, figura associada à visão noturna e muitas vezes chamada de Mira-Celi. Trata-se de uma travessia realizada no mar revolto da linguagem.
\end{abstract}

PALAVRAS-CHAVE: Poesia brasileira; Modernismo; Poesia e revelação; Poética; Mira-Celi.

\begin{abstract}
This report has as purpose to study Jorge de Lima's works in relation to the question of poetic revelation, Jorge de Lima's poetry, mainly after the publication of Time and Eternity, started to explore the process of literary creation as a theme. Thus, the poet as a messenger appears: he receives the flair which comes straight from
\end{abstract}

\footnotetext{
55 Pós-doutorando no Programa de Pós-Graduação em Ciência da Literatura (Poética) - Universidade Federal do Rio de Janeiro (UFRJ) - Docente da Universidade Estácio de Sá (UNESA) e do Centro Universitário Augusto Motta (UNISUAM), onde atua no Programa de Pós-Graduação em Linguagem e Tecnologia (Especialização) - E-mail: ataideveloso@bol.com.br
} 
God's hands. As a result, he has the responsibility to proclaim the greatest universal truths. The poet is compared to a hero who has supernatural power and is able to overcome the categories of time and space. In Jorge de Lima's concern, the act of poetic composition is related to the return to the origins of language - the moment when the magic and enchanting structures appeared. He sees in poetry a way to maintain the independence of language and to create his own particular world. The poet does not agree with the limits which a static language usually offers. On the other hand, he travels in order to catch his Muse, a character who is related to night dreams and is always called by Mira-Celi. It's a trip made in the choppy sea of language.

KEYWORDS: Brazilian poetry; Modernism; Poetry and revelation; Poetics; Mira-Celi.

\section{INTRODUÇÃO}

O desejo dos surrealistas de revolucionar a linguagem, fazendo incursões pelo inconsciente e valorizando o sonho e a memória, abriu as portas para que Jorge de Lima incorporasse à sua poesia uma temática permeada pelo misticismo judaico-cristão. Murilo Mendes, poeta e companheiro de Jorge de Lima, chegou a afirmar que o Surrealismo, ao buscar ultrapassar os limites da razão humana, em alguns momentos, aproximou-se bastante da mística.

A tentativa de Jorge de Lima de levar a cabo uma espécie de reatualização do texto bíblico se coaduna com o pensamento de Murilo Mendes, que considerava como o lastro da poesia as tradições mais antigas. Na poética limiana, o acesso ao sagrado assume um lugar central e o poeta exerce a função de um demiurgo, assim como Orfeu exerce a função de mediador entre os deuses e os homens.

\section{DESENVOLVIMENTO}

Unidos pelo mesmo objetivo: revelar ao homem verdades que sejam capazes de transcender tempo e espaço, Jorge de Lima e Murilo Mendes se propõem a escrever um livro a quatro mãos: Tempo e eternidade, cujo lema era "Restaurar a poesia em Cristo". 
Essa preocupação com a poesia de cunho espiritual, manifestada pelos dois escritores, está ligada à mudança de rumo ocorrida na vida de ambos. "Trata-se da conversão de Murilo Mendes ao catolicismo, coincidente o reatamento de Jorge de Lima com a religiosidade perdida na infância”. (ANDRADE, 1997, p.32).

Um dos fatos que contribuíram para tal mudança foi o recrudescimento das atividades de militância católica Dom Vidal, que tinha como líder Tristão de Ataíde. Desse grupo de caráter bastante heterogêneo que editava a revista $A$ ordem, faziam parte Jorge de Lima, Murilo Mendes e Ismael Nery, artista plástico e poeta bissexto. Foi o escritor Ismael Nery quem contribuiu para que os dois pilares da obra futura de Jorge de Lima e Murilo Mendes começassem a ser erguidos.

\footnotetext{
Por um lado, uma configuração particular do cristianismo milenarista, que se ocupa dos dois momentos limites propostos para a existência humana segundo a concepção judaico-cristã da história (a Criação e o Juízo Final); por outro, uma visão mítica, órfica do processo artístico, cuja inspiração estava no surrealismo. (ANDRADE, 1997, p.33).
}

A coletânea escrita a quatro mãos é dedicada a Ismael Nery; contudo, a importância desse artista para Tempo e eternidade não se resume à dedicatória. Além de aparecer em vários poemas, especialmente nos de Murilo Mendes, Nery é o idealizador da filosofia que impulsionaria a produção dessa coletânea de poemas. Ismael Nery reunia em sua casa, no Rio de Janeiro, amigos e intelectuais da época para discutir arte e filosofia, principalmente a corrente filosófica criada por ele: o Essencialismo.

Ismael Nery procurava traduzir esteticamente o Essencialismo, através de quadros e poemas, de modo que existia uma permeabilidade constante entre procedimentos artísticos e visão de mundo. O pensamento filosófico de Nery continha um aspecto híbrido: procurava unir a observação refinada do mundo das formas e um impulso. Para Ismael Nery, o mundo das formas somente poderia ser compreendido se fossem considerados os seus prolongamentos invisíveis. O importante é que se veja a poesia como um "centro de relações", exprimindo "a unidade da vida humana em suas múltiplas manifestações" (NERY apud MOURA, 1995, p.48). 
Foi essa exigência que levou Jorge de Lima e Murilo Mendes a fazerem uso constante de procedimentos combinatórios. O Essencialismo liga-se ao Surrealismo pelo fato de jamais se afastar de toda verdade dogmática, sempre valorizando formas diversificadas de experiência humana. Outro elemento que serve de ligação entre ambos é a aproximação do infinito e do religioso.

Em sua conferência “A mística e a poesia”, Jorge de Lima aponta alguns aspectos norteadores do seu projeto poético. Ele afirma que é inadmissível que o artista se distancie do sofrimento da humanidade: ele deve aceitar a sua missão de aproximar-se da massa e erguê-la à altura em que ele mesmo se encontra. (LIMA, 1935). A necessidade que o poeta tem de compartilhar as suas revelações com os demais homens também foi sentida por Murilo Mendes. Para ele, “A poesia não pode nem deve ser um luxo para alguns iniciados: é o pão cotidiano de todos, uma aventura simples e grandiosa do espírito.” (MENDES, 1945, p.40). Murilo Mendes mostra que, em todas as épocas, o poeta é incumbido não só de apresentar aos seus irmãos as mensagens a ele reveladas, mas de viver a vocação transcendente do homem.

A poesia tem a sua razão de existir no sobrenatural, sendo uma produção essencial do espírito. A crença no sobrenatural é a única forma de fazer com que a poesia tenha um rumo. Eliminar o caráter transcendental da poesia, através do materialismo, implicaria um abandono completo do seu sentido. Quanto mais artificializada e intencional for a poesia, menos ela estará próxima da verdadeira poesia. "O desenvolvimento do sentido poético da vida, preferivelmente ao sentido técnico e científico, é um dos aspectos principais da nova pedagogia que visa a formar o homem integral." (LIMA, 1935), escreve Jorge de Lima em “A mística e a poesia”.

Jorge de Lima reconhece que o homem moderno precisa recuperar o lado espiritual da vida, que foi abafado por uma supervalorização dos elementos materiais. O homem precisa ser regenerado a fim de que possa mostrar o vasto texto da criação. Devido a uma visão limitada, o homem moderno passou a defender a inexistência do mistério. Sua ação passou a ser diferençada não pela sua profundidade, mas sim pela sua enorme extensão:

Tal ação esbarra sempre num círculo vicioso: trata-se de produzir para obter o máximo rendimento material; e o rendimento material é aplicado em produzir, etc. Fabricam-se soldados, marinheiros e 
aviadores para justificar a produção de tanques, couraçados, e aviões; e fabricam-se estas máquinas aperfeiçoadíssimas que não poderão certamente ficar inertes, devendo ser usadas pelos soldados etc. É profundamente trágica a constatação de que o homem moderno só se diverte nas trincheiras ou nos cassinos. (MENDES, 1945, p.74).

Em sua conferência, Jorge de Lima enfatiza que a verdadeira poesia deve ser caracterizada por um componente litúrgico. Em consonância com este pensamento, Murilo Mendes afirma ser a liturgia uma comunicação da caridade que visa atingir os diferentes sentidos: uma lição de vida, que é revigora pelo influxo do Espírito Santo todos os dias. Murilo Mendes explica que viver liturgicamente implica a aceitação da atribulação. Além de procurar consolar os sofredores e visitar aqueles que se encontram em um leito de dor, a vida litúrgica busca dar liberdade aos oprimidos e alimentar os famintos.

O poeta é considerado um ser inspirado cujo dom tem procedência divina. Ele é uma espécie de imitação sobrenatural do criador - eleito por Deus para comunicar à humanidade uma realidade superior, transcendental. Deve, portanto, negar-se a si mesmo e deixar-se envolver pelo amor na sua forma mais pura. O caráter sobrenatural emerge no próprio início do processo poético, uma vez que a Graça Divina lhe é outorgada de maneira gratuita.

Para Jorge de Lima, o poeta já tem a sua missão designada desde a eternidade, assumindo, este, assim, a posição de um herói: capaz de superar, de ir e estar além das noções relacionadas a tempo e espaço. Tal aspecto da poética limiana, já observado em Tempo e eternidade, consolida-se em A túnica inconsútil, cujo texto de abertura, "Poema do cristão", revela o poder sobrenatural, do qual o poeta está investido para cumprir sua missão.

O poeta passaria a ter uma visão universal, capaz de locomover-se no tempo e no espaço, contemplando os limos primitivos e o ressoar das últimas trombetas. Os seus movimentos ficam tão alargados que ele se torna onipresente: encontra-se não só em Deus, mas também na matéria: "A poesia é a aventura no tempo e no espaço." (MENDES, 1945, p.51). O poder do poeta de decifrar diferentes códigos estaria acima do de qualquer indivíduo. Ele seria capaz de chegar à compreensão de qualquer signo, seja este verbal ou não-verbal: "Porque o sangue de Cristo/ Jorrou sobre os meus 
olhos,/ A minha visão é universal/ e tem dimensões que ninguém sabe.” (LIMA, 1997, p.351).

A ideia de que o poeta possui uma missão sobrenatural é reforçada por um dos poemas que se seguem: "O manto do poeta". Através do manto, recebido "pelas próprias mãos do Senhor", torna-se possível a transmissão de uma mensagem às nações de todas as épocas. O poeta é o prático do espírito. O manto concedido não é descrito como uma vestimenta comum: é associado à “túnica inconsútil” de Cristo:

E o manto do poeta lhe foi dado frente a frente e investido pelas próprias mãos do Senhor.

E o manto era talar e por fora tinha cordas de harpa para transmitir a todas as gerações o som de seus gestos e de seu andar.

E era belíssimo o manto do poeta e era obra de grande engenho: e era fio de escarlata com o número de suas tribos, com os sete dias da criação e a simbologia de suas musas. Traje tão imponente e tão sábio nunca houve antes dele desde o primeiro homem.

Dele nenhum vivente fora investido fora de seus iguais. E abaixo do manto havia a túnica interior em que o livre arbítrio permitia a inscrição das insígnias opostas.

E abaixo da túnica, havia a pele abrigando o sexo em todos os poros; mas um manto de pequenas chamas tornava-o sem mácula como um santo dentro da Graça.

(LIMA, 1997, p.353-354).

A poética limiana, principalmente após a publicação de Tempo e eternidade, passou a tematizar, com muita frequência, o processo de criação literária. Surge, então, a figura do demiurgo: o poeta que recebe o seu dom direto das mãos de Deus, tornando-se um anunciador das verdades universais. A figura do poeta, associada à de um herói com seus poderes sobrenaturais, é capaz de superar as categorias de tempo e espaço, conforme já frisado. 
Em "O poeta vence o tempo", o poeta torna-se controlador absoluto do tempo. Ele chega a mergulhar no passado remoto do "Velho Testamento", para encontrar Davi, o poeta-pastor que, acompanhado de sua harpa, compõe inúmeros salmos. A fim de tentar se libertar das "correntes" que o mantêm aprisionado à finitude da vida, o poeta, como se estivesse realizando uma viagem, vai em busca dos valores da "Eternidade":

Já não vejo mais a paisagem de plantas carnívoras.

Levada pelos riachos a água velha canta de novo.

A relva ignora sua tragédia e alteia as folhas inocentes.

Regresso ao teu tempo, Davi.

Como tu tenho harpa e tenho Deus.

E num dia bíblico assim

fora dos tempos duros

posso voltar às origens,

e sentir como tu

que sou mais forte que o rei,

mais forte que todos os Golias.

Mas não sei como tu

distinguir se essa estrela claríssima

é a estrela da manhã

ou se é mesmo a poesia

que nós vemos no céu

- antecedente e posterior a tudo.

(LIMA, 1997, p.338).

O poeta identifica-se com o pastor e expressa o seu desejo de ser mais forte que o rei e superior a todos os gigantes. A conjunção adversativa "mas" introduz o reconhecimento de uma limitação: assim, como Davi, não consegue diferenciar a iluminação poética, metaforizada numa estrela, da própria poesia, que é evocada, aqui, no seu aspecto mais primitivo, "antecedente e posterior" a todas as coisas.

No poema acima, observa-se que o eu-lírico regressa a um período em que predominavam as comunidades agrícolas e pastoris, semelhantes às da época arcaica, em que Hesíodo viveu e compôs os seus cantos. A poesia de Hesíodo retrata um tempo anterior à invenção da pólis, do alfabeto e da moeda. Nessa época, o aedo (poeta- 
cantor) "representa o máximo poder da tecnologia da comunicação" (TORRANO, 1995, p.16). O poeta, através do seu canto, tem a função de transmitir ao grupo social ao qual pertence toda a visão de mundo e consciência de sua própria história. No poema, o poeta deseja ficar "fora dos tempos duros" a fim de que possa, assim como Davi, ter acesso à poesia em seus primórdios, "antecedente e posterior a tudo".

Ao ouvir o canto do poeta, o homem comum passava a ter a possibilidade de superar os seus limites de movimento e visão, "[...] transcender suas fronteiras geográficas e temporais, que de outro modo permaneceriam infranqueáveis, e entrar em contato e contemplar figuras, fatos e mundos que pelo poder do canto se tornam audíveis, visíveis e presentes" (TORRANO, 1995, p.16).

A flexibilidade apresentada pelo poeta, que lhe permite deslocar-se por diversas direções, é considerada por Octavio Paz um componente significativo do "sagrado". Paz afirma ser o divino o responsável por alterar mais intensamente as noções de tempo e espaço, consideradas por ele como os elementos responsáveis por nortear a nossa maneira de pensar:

A experiência do sagrado afirma: aqui é lá; os corpos são ubíquos; o espaço não é uma qualidade; ontem é hoje; o passado regressa; o futuro já aconteceu. Se se examina de perto essa maneira de passar que têm o tempo e as coisas, percebe-se a presença de um centro que atrai ou separa, eleva ou precipita, move ou imobiliza. (PAZ, 1982, p.153).

Octavio Paz associa também o sobrenatural à sensação de estranheza, que tem o poder de interditar não só a realidade, mas também a própria existência. São as cerimônias religiosas que contribuem para criar um aspecto duplo: ao mesmo tempo, encontramo-nos diante do real e do irreal, pois todo rito assume a forma de uma representação e todo indivíduo que toma parte dele está, na verdade, desempenhando o papel de um ator. Quando ele representa, está simultaneamente presente e ausente do personagem. Para o crente, ele está dentro e fora do mundo, pois o mundo é real e também irreal.

No "Poema do cristão", de A túnica inconsútil, o poeta é visto como um grande mágico, um palhaço, um louco, revelando, assim, o seu aspecto deformador, resultante 
do seu caráter múltiplo, o que o aproxima do herói dos Cantos, de Pound: "um ser exaltado, tempestuoso e sarcástico, ao mesmo tempo esteta, profeta e clown" (PAZ, 1982, p.97). Ele tem a vida eterna e consegue se sobrepor às leis da natureza. Como numa profecia, tempo e espaço se fundem e se transgridem simultaneamente:

Venho e irei como uma profecia, sou espontâneo como a intuição e a Fé.

Sou rápido como a resposta do Mestre, sou inconsútil como a Sua túnica, sou numeroso como a Igreja, tenho os braços abertos como a sua Cruz despedaçada e refeita todas as horas, em todas as direções, nos quatro pontos cardeais; e sobre os ombros A conduzo através de toda a escuridão do mundo, porque tenho a luz eterna nos olhos. E tendo a luz eterna nos olhos, sou o maior mágico: ressuscito na boca dos tigres, sou palhaço, sou alfa e ômega, peixe, cordeiro, comedor de gafanhotos, sou ridículo, sou tentado e perdoado, sou derrubado no chão e glorificado, tenho mantos de púrpura e de estamenha, sou burríssimo como São Cristóvão, e sapientíssimo como Santo Tomás. E sou louco, louco, inteiramente louco, para sempre, para todos os séculos, louco de Deus, amém!

(LIMA, 1997, p. 351-352).

O penetrar no mundo do sagrado se dá através do que Kierkegaard chama de "salto". Octavio Paz compara também esse "salto moral” à experiência central do budismo. Nessa religião, estar ligado ao mundo implica necessariamente uma adesão ao viver e ao morrer, ou seja, significa pertencer a esta margem. "Ao nos desprendermos do mundo objetivo, não há morte nem vida, e ficamos como a água correndo incessantemente; a isso se chama: a outra margem." (SUZUKI apud PAZ, 1982, p.147).

Na poética limiana, esse salto que conduz ao sagrado é, em diversos momentos, metaforizado por uma viagem marítima. Quase sempre, o poeta encontra-se prestes a sucumbir em meio à escuridão de uma horrível tempestade, mas consegue vencer a 
tormenta no momento em que surge uma "mão enorme" capaz de sustentar a nau, impedindo, assim, o naufrágio. Mais uma vez, ao apresentar o seu canto, o poeta é revestido de um poder sobrenatural e esse poder sempre procede de Deus.

Dentro da noite, da tempestade,

a nau misteriosa lá vai.

O tempo passa, a maré cresce,

o vento uiva.

A nau misteriosa lá vai.

Acima dela

que mão é essa maior que o mar?

Mão de piloto?

Mão de quem é?

A nau mergulha,

o mar é escuro,

o tempo passa.

Acima da nau

A mão enorme

sangrando está.

A nau lá vai.

O mar transborda,

as terras somem,

caem estrelas.

A nau lá vai.

Acima dela

a mão eterna

lá está.

(LIMA, 1997, p.323-324).

A estrutura arquitetônica de "A mão enorme" vem reforçar a imagem da mão enorme que sustenta a embarcação. Nem mesmo o uivar do vento explorado no poema pela aliteração do /v/ em "vento, uiva, vai", a escuridão e o transbordamento do mar, o desaparecimento das terras e das estrelas conseguem fazer com que a nau soçobre. $\mathrm{O}$ 
poema pode ser visto como uma tradução plástica da presença de Deus, simbolizada pela "mão enorme".

Para Jorge de Lima, o ato de composição poética está ligado ao retorno aos primórdios da linguagem - momento de surgimento das fórmulas mágico-encantatórias. Ele vê na poesia uma forma de manter a autonomia da linguagem e de criar o seu mundo particular. O poeta não está conformado com os recursos que uma linguagem estática pode oferecer-lhe. Muito pelo contrário, realiza uma verdadeira viagem em busca de sua Musa, figura geralmente associada à visão noturna e muitas vezes chamada de Mira-Celi. É uma travessia realizada no mar revolto da linguagem. O mito aqui evocado é o de Orfeu, que está ligado não só à criação literária, mas também à fundação de religiões importantes.

A princípio, Orfeu era praticante da religião de Apolo, desempenhando a função de sacerdote. Ao se converter à religião de Dioniso, deu origem ao orfismo: religião proveniente da reforma religiosa de Dioniso, de acordo com o espírito de Apolo. Orfeu tornou-se conhecido por desenvolver as atividades de músico, poeta, cantor, sendo mesmo uma espécie de herói civilizador. O som encantador da sua lira tinha o poder mágico de seduzir os elementos da natureza. Homens e animais selvagens se rendiam ao seu fascínio. Após a sua conversão ao culto dionisíaco, Orfeu passou a desempenhar a função de ensinar às outras pessoas os segredos da nova religião.

Os Argonautas, de Apolônio de Rodes, no terceiro século antes de Cristo, relatanos a participação de Orfeu na aventura dos marinheiros da nau Argos, ao tentarem recuperar o velocino de ouro, que estava sob a guarda de um dragão. Através da força sedutora do seu canto, Orfeu se destacou bastante na realização do referido empreendimento. Ele conseguiu colocar sob controle as forças tempestuosas do homem e da natureza, atuando como um líder espiritual (CARVALHO, 1990, p.16).

Orfeu apaixonou-se pela ninfa Eurídice, com quem se casou. Entretanto, a felicidade de ambos foi de pouca duração, pois, num determinado dia, ao estar colhendo flores, Eurídice foi picada por uma serpente, vindo a falecer. Desiludido com a morte da amada, Orfeu decidiu procurá-la no Hades, região subterrânea para onde eram enviadas as sombras dos mortos. Depois de conseguir transpor inúmeros obstáculos, chegou, finalmente, ao lugar onde se encontravam os deuses do Hades (Plutão e Perséfone). Ao tanger a sua lira, foi capaz de comover os soberanos do mundo das trevas. A sua esposa 
lhe foi devolvida, mas foi estabelecida uma condição: não olhar para trás antes de deixar o Hades. "Já estando, porém, próximos à luz, assaltado pela dúvida de que a amada não o estivesse seguindo, ele olhou para trás e pagou caro a sua transgressão à ordem dada." (SILVA, 2000, p.48). Ele viu a sua amada, Eurídice, extinguir-se na escuridão.

Após o término da viagem ao Hades, Orfeu passou a revelar o conhecimento adquirido naquele lugar, já que lhe fora permitido o privilégio de ter acesso a outro mundo. O canto de Orfeu passa a ser, então, superior ao de todos os outros aedos:

Enquanto os aedos e os citaredos celebravam altos feitos dos homens ou dos deuses mas sempre em intenção de um grupo humano, a voz de Orfeu começou além do canto que recita e conta. Trata-se de uma voz anterior à palavra articulada, e cujo estatuto de exceção é marcado por dois traços: um designa Orfeu para o mundo a música antes do verso, a música sem palavra, um domínio onde ele não imitava ninguém, onde ele era o começo e a origem. (DETIENNE, 1991, p.87).

Jorge de Lima, ao retomar o mito de Orfeu, não tem como único objetivo empreender uma volta às tradições, mas criar um pretexto para a reflexão através de um jogo de símbolos, fazendo nascer uma nova escritura do mito e dando-lhe um novo sentido.

A figura do poeta, de Tempo e eternidade em diante, encontra-se revestida de uma missão especial: pregar "novas verdades" aos homens. Orfeu, que significa o poeta por excelência, passa a ser a figura central de um grande número de poemas. Em "Distribuição da poesia", o poeta se iguala a um homem comum e considera a todos como seus irmãos, fazendo referências a diversas classes de trabalhadores: estalajadeiros e bufarinheiros.

Mel silvestre tirei das plantas, sal tirei das águas, luz tirei do céu. Escutai, meus irmãos: poesia tirei de tudo para oferecer ao Senhor. 
Não tirei ouro da terra

nem sangue de meus irmãos.

Estalajadeiros não me incomodeis.

Bufarinheiros e banqueiros

sei fabricar distâncias

para vos recuar.

A vida está malograda,

creio nas mágicas de Deus.

Os galos não cantam,

a manhã não raiou.

Vi os navios irem e voltarem.

Vi os infelizes irem e voltarem.

Vi os homens obesos dentro do fogo.

Vi ziguezagues na escuridão.

Capitão-mor, onde é o Congo?

Onde é a Ilha de São Brandão?

Capitão-mor que noite escura!

Uivam molossos na escuridão.

Ó indesejáveis, qual o país,

qual o país que desejais?

Mel silvestre tirei das plantas,

sal tirei das águas, luz tirei do céu.

Só tenho poesia para vos dar.

Abancai-vos, meus irmãos.

(LIMA, 1997, p.321).

O poeta reconhece que se encontra numa situação distinta, não por ser superior, mas por ter em suas mãos a poesia. Tendo recebido esta das mãos do Senhor, passa a devolvê-la a toda humanidade e também a Deus. A anáfora presente nos primeiros e nos últimos versos de "Distribuição da poesia" vem reforçar o papel de profeta desempenhado pelo poeta. Assim como Orfeu se tornou fundador de uma nova religião e arquétipo do poeta como profeta e demiurgo, o poeta, nos textos limianos, comunica ao homem mensagens capazes de transcender o Tempo e atingir a Eternidade. 
Nos textos de Jorge de Lima, o poeta parte para o conhecimento de um mundo paralelo, só que de caráter um tanto diverso do Hades. No Livro de sonetos, o poeta dirige-se para um mundo administrado por imagens insólitas. Um dos eixos que permite vislumbrar uma unidade temática é a problematização da criação poética. No soneto "Como sombra invasora e transbordada", o componente surrealista e o aspecto órfico são claramente integrados:

\author{
Como sombra invasora e transbordada \\ de asa de cinza e chuva quebradiça \\ tu desterras o tempo interrompido \\ com tua solidão alucinada. \\ Pedra de olvido e fonte abandonada, \\ essa faixa de névoa é tão perdida \\ que morre e nasce em ti, se em mim tu inclinas \\ tua distância em plumas desfolhada.
}

De cal flutuante e de onda descontínua Musa és tão só, tão mar ensimesmado tão sortilégio, tão solitária e erma

que pareces escada submarina para eu descer imerso, no teu reino investido dos mantos decisivos.

(LIMA, 1997, p.485).

Os limites existentes entre o sono e a vigília acham-se rompidos; o poeta mergulha no mais profundo dos mares a fim de encontrar a sua Musa. A partir dessa descida às regiões oceânicas mais escuras e desconhecidas, sugerida pela presença de uma "escada submarina", observa-se a presença do mito de Orfeu. Enquanto Orfeu desce às profundezas do Hades para buscar Eurídice, o poeta, no referido soneto, imerge no fundo para encontrar-se com a Musa. Ao estar em contato com ela no espaço escuro do fundo do oceano, o poeta se sente à vontade. A escada submarina, no último terceto do soneto, conduz o poeta ao reino das palavras. 
Reconhece-se no soneto uma “[...] certa atmosfera mítica, seu caráter visionário e órfico, uma tendência ao isolamento orgulhoso do sujeito lírico, criador de um microcosmo particular.” (ANDRADE, 1996, p.130). Entretanto, nesse mundo de características peculiares, o poeta não demonstra interesse em relatar as suas impressões ou em descrever os seus sentimentos diante de um acontecimento banal. $\mathrm{O}$ seu olhar se desprende do corriqueiro e volta-se para o cósmico, ou seja, liberta-se do particular e dirige-se para aquilo que abrange toda a humanidade.

É importante ressaltar que a figura da Musa é associada a imagens insólitas, contribuindo, assim, para a formação de um mundo sobrenatural e onírico, como os surrealistas se propunham a criar. "A descoberta da poesia está expressa como um encontro súbito com uma musa distante e fugidia.” (ANDRADE, 1996, p.132). A aparição da musa é comparada a uma "sombra invasora", acompanhada de "asa de cinza" e de "chuva quebradiça", além de ter o poder de "desterrar o tempo interrompido", a partir da alucinação da sua própria solidão.

O estranho também se instaura no poema através da mudez, isolamento e solidão da musa e do seu lugar de habitação ("Musa és tão só, tão mar ensimesmado/ tão sortilégio, tão solitária e erma”). Em vez de se posicionar em um local determinado para melhor compartilhar com o poeta a força da linguagem através de um canto mágico e colocar nos lábios deste a palavra poética, a musa do soneto trafega livremente pelo fundo do oceano como "cal flutuante" e "onda quebradiça". O poeta é obrigado a se deixar levar pelo canto sedutor da Musa a fim de ser investido dos "mantos decisivos" que esta lhe confere.

A diluição de contornos, ao apresentar a figura da Musa e a indefinição do ambiente marítimo, sugere a aproximação do poeta com o mundo dos sonhos no momento de revelação poética. "A visita da poesia não se dá ao alcance de uma decisão racional, a partir de mero cálculo de meios e fins. Não se pode convocar a musa como quem aciona um interruptor e acende as luzes." (ANDRADE, 1996, p.135). É interessante notar que, no soneto, a experiência do poeta com a Musa é semelhante à do poeta com as palavras: ambas fogem ao normal ou habitual.

\section{CONCLUSÃO}


Através da imaginação, Jorge de Lima reconstrói paisagens e acontecimentos da infância, tendo sempre o poder da memória como aliado. Pela força da canção, o poeta permite que se toque o impalpável e que se escute o silêncio coberto por uma paisagem destruída pela insônia. "O testemunho poético revela outro mundo dentro deste, o mundo outro que é este mundo. Os sentidos, sem perder seus poderes, convertem-se em servidores da imaginação e nos fazem ouvir o inaudito e ver o imperceptível." (PAZ, 1999, p.11).

Assim, os portais do sagrado se abrem para o poeta e este passa a ter uma visão universal, capaz de locomover-se no tempo e no espaço. A poesia passa a ser o testemunho dos sentidos. A poesia é resultado de um tecido composto de palavras que se enlaçam e emitem reflexos e até nuances. Tudo que é mostrado no poema deve ser visto não com os olhos da matéria, mas com a visão do espírito. Os sentidos pertencem e não pertencem a este mundo - é através deles que a poesia consegue erguer uma ponte entre o que se vê e o que se crê.

\section{REFERFÊNCIAS}

ANDRADE, F. de S. O engenheiro noturno. São Paulo: EDUSP, 1997.

A Musa Quebradiça. In: BOSI, A. (Org.). Leitura de poesia. São Paulo: Ática, 1996. p. 125-140.

CARVALHO, S. M. (Org.). Orfeu, orfismo e viagens a mundos paralelos. São Paulo: UNESP, 1990.

DETIENNE, M. A escrita de Orfeu. Tradução Mário da Gama Kury. Rio de Janeiro: J. Zahar, 1991.

LIMA, J. de. Poesia completa. Rio de Janeiro: Nova Aguilar, 1997.

A mística e a poesia. Jornal de Letras, Rio de Janeiro, out. 1952 / jun. 1953.

MENDES, M. O discípulo de Emaús. Rio de Janeiro: Agir, 1945.

MOURA, M. M. de. Murilo Mendes - A poesia como totalidade. São Paulo: EDUSP, 1995.

PAZ, O. O arco e a lira. Tradução Olga Savary. Rio de Janeiro: Nova Fronteira, 1982. A dupla chama: amor e erotismo. Tradução Wladyr Dupont. São Paulo:

Siciliano, 1999. 
SILVA, F. P. L. da S. Murilo Mendes: Orfeu transubstanciado. Viçosa, MG: UFV, 2000.

TORRANO, J. O mundo como função das musas. In: HESÍODO. Teogonia: a origem dos deuses. Tradução e estudo Jaa Torrano. São Paulo: Iluminuras, 1995. p.11-101.

Artigo recebido em 03/05/2010. Aceito para publicação em 11/07/2010. 